\title{
Imágenes de sobrevivencia: del realismo urbano del Grupo Chaski al Perú contemporáneo de Claudia Llosa.
}

\section{Images of Survival: of the Urban Realism of the Chaski Group to Peru Contemporary of Claudia Llosa.}

\begin{abstract}
Resumen
El artículo analiza los trabajos iniciales del Grupo Chaski y de Claudia Llosa, dos puntos de referencia en el cine peruano contemporáneo. A través de la crítica al argumento y las características de las películas de estos cineastas, se construye una imagen del Perú, un país que volvió a la democracia en 1980 y, desde entonces, ha sido gobernado por presidentes posteriormente acusados de corrupción y abuso de poder como Alan García, Alberto Fujimori, Alejandro Toledo y Ollanta Humala. Las películas de Chaski inciden en la pobreza y vulnerabilidad de niños enfrentados a la gran ciudad, Lima, y se anticipan a ese cine de la marginalidad que en los años 90 produjo cintas tan logradas como Pizza, birra, faso, La vendedora de rosas, Ciudad de Dios o Ratas, ratones, rateros. La obra de Claudia Llosa, por su parte, llamó la atención internacional por el triunfo de su segunda película, La teta asustada, en el Festival de Berlín. Esta película, que marca una continuidad respecto de la primera, Madeinusa, es un retrato de los años posteriores a la guerra interna, los de la barbarie de Sendero Luminoso y la respuesta de las Fuerzas Armadas. El artículo aspira a ofrecer, a través del análisis cinematográfico, una mirada global de la sociedad peruana de los últimos treinta años, marcados por la pobreza estructural, el terrorismo, la aplicación de reformas neoliberales y la corrupción a todo nivel del Estado.
\end{abstract}

Palabras claves Cine Peruano, Claudia Llosa, Grupo Chaski, Marginalidad, Crisis Social, Neoliberalismo.

\begin{abstract}
The article analyzes the first films of the Grupo Chaski and Claudia Llosa, two strong references in the Peruvian cinema of the last thirty years. Through the critique of the ideas and characteristics of these movies, the essay tries to build a image of Peru, a country where democracy returned in 1980 and since then he has had presidents accused of corruption and
\end{abstract}


abuse of power such as Alan García, Alberto Fujimori, Alejandro Toledo and Ollanta Humala. The works of Chaski focus on poverty and vulnerability of children in Lima, a big city, capital of the country, in the 1980s. In this sense, they are previous stories to "cine de la marginalidad" that in the 1990s featured movies so realistic like Pizza, birra, faso, La vendedora de rosas, Ciudad de Dios or Ratas, ratones, rateros. Claudia Llosa's work, called international attention when her second film, La teta asustada, won the Golden Bear, the main prize at Berlin Festival. This film, that establishes a necessary continuity to her first film, Madeinusa, is a portrait of the postwar years in the Peruvian Andes, those of the violence of Sendero Luminoso and how the Army designed a destructive strategy. The article looks for an overview of Peruvian society of the last thirty years, characterized for the structural poverty, terrorism, the development of neoliberal reforms and the corruption of the State at different levels.

Keywords Peruvian Cinema, Claudia Llosa, Grupo Chaski, Marginalty, Social Crisis, Neoliberalism.

En julio de 1982, a solo dos años del retorno del Perú a la institucionalidad democrática, después de dos regímenes militares (1968-1980), tuvo lugar en Lima, la ciudad capital, el concurso de belleza "Miss Universo", que contó con el auspicio del gobierno del arquitecto Fernando Belaunde, un admirador de las formas de la política tradicional y quien ya había sido presidente del país en los años $60^{1} \mathrm{El}$ Grupo Chaski, un colectivo de cineastas que por entonces realizaba sus primeros trabajos, eligió centrarse a fondo en el engranaje y la influencia de los medios de comunicación, sobre todo la televisión, y su relación con el certamen de belleza, para proponer una mirada crítica, cuestionadora, realista de la sociedad peruana.

En tanto la televisión privada mostraba anuncios comerciales que incidían en los patrones de belleza occidentales así como en el consumo de productos de marcas nacionales que eran promovidos en torno al concepto de patria --como si

\footnotetext{
${ }^{1}$ Fernando Belaunde Terry gobernó por primera vez el Perú entre 1963 y 1968, año en que fue derrocado por una Junta Militar encabezada por el general Juan Velasco Alvarado. El régimen de Velasco intentó una transformación de las estructuras socioeconómicas del país y promulgó la ley de reforma agraria. En 1975, con el general Francisco Morales Bermúdez al mando, se inició una segunda fase del gobierno militar, represiva y confrontacional, que, ante la presión ciudadana y de los partidos políticos, finalmente convocó, primero, a una Asamblea Constituyente, y poco después, a elecciones presidenciales. En 1980, Fernando Belaunde retornó al poder, tras imponerse a candidatos del Apra, el Partido Popular Cristiano y movimientos de izquierda, tanto moderados como violentistas.
} 
CATEDRAL TOMADA: Revista de crítica literaria latinoamericana / Journal of Latin American Literary Criticism Imágenes de sobrevivencia: del realismo urbano del Grupo Chaski al Perú contemporáneo de Claudia Llosa.

el Perú fuera una república unida, sin traumas sociales, económicos o culturales--, las imágenes del cortometraje "Miss Universo en el Perú" contrastaban esa muestra "optimista" y "nacionalista" de los medios electrónicos frente a una realidad totalmente opuesta: registros de la pobreza, tomas de los entonces llamados "pueblos jóvenes" (hoy conocidos como "asentamientos humanos"), declaraciones de ciudadanas que se sentían agredidas por un concurso de belleza que, como "Miss Universo", "cosificaba" y limitaba a la mujer desde su misma esencia, en pro de la comercialización de su figura, al amparo del capital transnacional, en un mundo a donde aún el término "globalización" no había llegado.

El Grupo Chaski aplicó en este documental un constante montaje alterno en el que se sucedían imágenes del concurso de belleza o los preparativos y ensayos de las participantes, además de sus giras y paseos por la ciudad. En contraste, se mostraban los rostros de mujeres de distinta edad, espectadoras pasivas que miran con sorpresa, admiración o tan solo observan las imágenes que la televisión reproduce. A propósito de esta afirmación, podemos citar a Sophia McClennen, quien señala:

In a brilliant use of Eisensteinian montage, the documentary juxtaposes images of the pageant with images of girls and women watching the pageant. The contrast between the European features of the contestants, especially when these hail from Latin American countries, and the indigenous features of the spectators highlights the ways that conflicting value systems cause social damage. (McClennen)

A la belleza que está muy cerca de la idealizada por las divas de Hollywood, se oponen los rostros de mujeres andinas, ya no solo espectadoras, sino, por ejemplo, las que protestan en medio de su participación en un congreso de una confederación campesina. Nuevamente, S. McClennen se refiere a este contexto: 
But Chaski's aesthetic pushes the critique even further by adding a few key twists to this form of political montage. First, the editing holds on the face of the indigenous-featured woman longer than one might expect. This slowing down of time coupled with the unclear expression on the woman's face and the absence of a context for her viewing, produces a profound unease in the viewer. (McClennen)

En este documental, los miembros del Grupo Chaski revelan su particular interés por un cierto origen y desarrollo de la relación entre medios electrónicos y espectadores, que a veces resulta muy subjetiva, en el sentido no solo que puede devenir en influyente y manipuladora sino también en que captura y aliena la mente de los receptores. Debido a ello, la cámara registra, no por mera coincidencia, los mensajes subliminales de los anuncios comerciales (como cuando se asocia el rostro y cuerpo de una mujer al de una botella de cerveza) y da cuenta, de esta manera, que dicha forma de tratar al sexo femenino no solo se da en la fugacidad de un concurso internacional de belleza sino en la permanente invasión de avisos por televisión, cuyo objetivo primordial es el consumo de marcas y productos.

La estética de Chaski potencia la riqueza del lenguaje audiovisual --la alternancia de imágenes de noticieros, escenas del concurso, tomas de las barriadas de Lima, testimonios en contra del certamen de belleza--, y logra crear un esquema binario: en un primer caso, un mundo de fantasía y evasión, y por lo tanto inalcanzable, que es promocionado por la televisión, la cual "vende" este "paraíso". En un segundo caso, las tomas evidencian casos extremos de una lacerante pobreza en el Perú y muestran, además, ese lado "gris" propio de la ciudad capital, ya señalado en los años 50 por Sebastián Salazar Bondy en su clásico ensayo Lima la horrible.

Chaski incide en la muestra de estas ambivalentes y enrarecidas oposiciones, derivadas no solo de la intromisión extranjera, a través de "Miss 
CATEDRAL TomadA: Revista de crítica literaria latinoamericana / Journal of Latin American Literary Criticism Imágenes de sobrevivencia: del realismo urbano del Grupo Chaski al Perú contemporáneo de Claudia Llosa.

Universo", y del modo cómo un sistema capitalista --durante los años 80, cuando los problemas financieros más acuciantes de las repúblicas latinoamericanas eran la deuda externa o la espiral inflacionaria-- puede generar circuitos de evasión para "distraer" a la población o, por instantes, simular que el mundo real, de cada día, puede ser suplantado por otro colmado de vanas ilusiones.

\section{Chaski, retratos de pobreza y marginalidad en una ciudad monstruosa}

Integrado inicialmente por Fernando Espinoza, Alejandro Legaspi, Stefan Kaspar, María Barea y Fernando Barreto, Chaski mantuvo su preocupación social y realizó dos largometrajes sobre niños que se enfrentan a la gran ciudad, Lima, en busca de sobrevivir. Gregorio (1984) y Juliana (1989) son hasta hoy puntos de referencia de un cine que, basado en una estética y principios deudores del Neorrealismo y enfocándose en la calles de la ciudad como el gran lugar de desplazamiento, testimonió la grave crisis de una infancia abandonada a su propia suerte. La propuesta ideológica y estética de Chaski prolonga una tradición tan frecuente como impactante en el cine latinoamericano, cuyo punto de partida podría situarse en la célebre película de Luis Buñuel, Los olvidados (México, 1950).

La estética miserabilista del Grupo Chaski guía a la cámara que registra, por ejemplo, la escasez de oportunidades en una ciudad semicolonial como Lima, las abultadas calles del centro de la urbe, los desórdenes de la multitud, o imágenes de apresurados transeúntes. Así, se elabora y desarrolla una "activa" mirada crítica a partir de las carencias de una metrópoli en constante y desordenada expansión. En Gregorio y Juliana, Chaski no solo va a prolongar esta estética miserabilista sino que va a extender su compromiso político, su pacto consciente con la mirada realista y cuestionadora.

El primer largometraje del Grupo Chaski, Gregorio, gira en torno a la vida de un niño que migra de un pueblo andino a Lima con su familia. La gran ciudad, 
de la que todos hablan con asombro y temor, genera en el protagonista una serie de sensaciones y conductas que evidencian su incapacidad para adaptarse al nuevo ambiente. Su familia participa de una "invasión" de tierras, y levanta una casa de esteras en el arenal.

Al poco tiempo el padre, enfermo, muere. Entonces, Gregorio comienza a trabajar como lustrabotas (evidente alusión a uno de los filmes fundamentales de uno de los maestros del Neorrealismo, Vittorio de Sica, El lustrabotas, 1946). Además, "reforzaban también la actitud realista, el anonimato de los rostros de varios de los actores (niños desconocidos, actores de teatro barrial, marginal o "de grupo”) y sobre todo la intención de alertar la conciencia dormida del espectador" (Bedoya 275).

Gregorio se convierte en un niño de la calle. Llega por las noches a su casa y entrega el escaso dinero que ha ganado a su madre. Una concepción sociológica de esta situación es la que ofrecen Yves Predrazzini y Magaly Sánchez:

El niño de la calle es antes que nada un excluido del proceso educativo y de la socialización tradicional (cuyos pilares ideales son todavía la familia, la escuela y el trabajo). El niño escapa frecuentemente de una relación familiar profundamente deteriorada, que se fundamenta en los maltratos, servicios y explotación por parte de los padres, provocada generalmente por las condiciones de gran miseria económica y por ende física y afectiva. (100)

La estética de la pobreza, de la exclusión, de la marginalidad, replanteada por Chaski, reproduce la "realidad real" (término que Mario Vargas Llosa utiliza en García Márquez: Historia de un deicidio, para diferenciar la "realidad" de la literatura frente a la realidad tal cual), una vez más denunciando la injusticia del capitalismo industrial: por ejemplo, en el recorrido de Gregorio y sus amigos por Miraflores, un distrito turístico de Lima, en el cual, a los avisos de neón y los restaurantes y almacenes, síntomas de cierta "modernidad", se opone el registro 
CATEDRAL TomadA: Revista de crítica literaria latinoamericana / Journal of Latin American Literary Criticism Imágenes de sobrevivencia: del realismo urbano del Grupo Chaski al Perú contemporáneo de Claudia Llosa.

de los robos y asaltos que ellos practican. La mendicidad y la miseria obligan a estos pequeños hombres a convertirse en delincuentes, para los cuales no existe un futuro (recordemos, para el caso, el título y el contenido de la primera película de Víctor Gaviria, Rodrigo D No Futuro, a su vez una referencia directa a Umberto $D$, de Vittorio de Sica, filme neorrealista, uno de los más tristes y desencantadores de la historia del cine).

Mientras tanto, las calles del centro de la ciudad y otras aledañas se muestran descuidadas, las paredes desvencijadas (como en las películas de Arturo Ripstein, Profundo carmesí y Principio y fin, ambas concebidas como profundos dramas humanos), desordenadas, interrumpidas cada cierto tramo por restos de basura. La representación de este paisaje urbano, abandonado, insiste en una anomia creciente, en el descuido tanto de las autoridades como el comportamiento de los ciudadanos. Ni a unos ni a otros parece importarles la convivencia o el ornato de la ciudad, existen problemas más graves y urgentes. La búsqueda de un porvenir ha quedado atrás. Solo queda la sobrevivencia, inmediata, a cualquier precio. La cámara registra minuciosamente esta realidad y, al hacerlo, le otorga una dimensión que va más allá de lo puramente común. El cine, entonces, una vez más se convierte en un instrumento de reflexión, en un arte que más allá del didactismo nos lleva a cuestionar y a conocer realidades y situaciones que pueden permanecer ocultas o estar borradas del imaginario social, colectivo. El cine es una herramienta que abre la conciencia y la conduce hacia otros caminos, no solo como como ocurre en el caso de Chaski sino como ocurriría en la década de los 90 y principios del siglo XXI con películas que también tematizaban temas de violencia y marginalidad como La vendedora de rosas, Sicario, Pizza, birra, faso, Ratas, ratones, rateros, Ciudad de Dios y Amores perros.

La música incidental de Arturo Ruiz del Pozo se incorpora a las situaciones de tensión, que no son escasas en la película. A veces, los tonos se aceleran, cuando los acontecimientos parecen ir desbocados, como en una fuga, mientras advertimos que en esta historia nunca hay calma, que un frenético día 
repite al anterior y anticipa el siguiente con su misma y dolorosa frustración y escasez.

En tanto en un país como el Perú, que aún tiene mucho de colonial, no se alteren las estructuras tradicionales de poder y dominación, así se invoque la vigencia de una democracia, simplemente referencial para los que no se sienten representados por ella, seguiremos constatando a diario la vigencia de niños como Gregorio, huérfanos absolutos de cualquier beneficio.

El valor de Gregorio, que también puede ser interpretado como un docudrama, reside en su muestra de una realidad común, citadina, propia no solo de Lima sino de otras grandes ciudades de América Latina. Ya el desplazamiento del grupo de niños por Miraflores se asemeja a ese tránsito que parece nunca acabar en Medellín, protagonizado por los menores de La vendedora de rosas en la Nochebuena, atrapados por el consumo de drogas y estimulantes.

En Juliana (1989), su segundo largometraje, el Grupo Chaski eligió a una adolescente para continuar su tratamiento visual y expresivo sobre la pobreza en Lima, los niños abandonados, que casi siempre huyen de su hogar y tienen que enfrentarse tempranamente a las exigencias de la vida. Si Gregorio era un niño migrante, que llegaba desde un pueblo andino a la capital, Juliana se ve obligada a dejar su casa, en una barriada, porque ya no soporta el comportamiento ni los abusos de la segunda pareja de su madre, un hombre entregado a la bebida y sin ánimo ni deseos de trabajar, que espera que las mujeres de su hogar velen por él.

Esta característica puntualiza un síntoma común en muchos países de la región, en los cuales, a pesar de avances cada vez más frecuentes, la liberación plena de la mujer y su profesionalización en el trabajo, es todavía un logro por alcanzar. Gozar de una autonomía total, como consecuencia de una legislación ad hoc, y superar el prejuicio de una sociedad católica tradicional, permitiría a la mujer hacer realidad aspiraciones y deseos, injusta y secularmente negados o prohibidos en contextos marcadamente patriarcales, en los cuales el machismo, con toda su carga de dolor y violencia, impone, sin más, su absoluta autoridad. 
CATEDRAL TOMADA: Revista de crítica literaria latinoamericana / Journal of Latin American Literary Criticism Imágenes de sobrevivencia: del realismo urbano del Grupo Chaski al Perú contemporáneo de Claudia Llosa.

Juliana se dedica a limpiar tumbas en un cementerio, y prolonga su jornada deambulando por las calles, ya que en su casa no encuentra ninguna realización. Como en Gregorio, el Grupo Chaski recurre otra vez a las tomas de vehículos de transporte urbano, que contaminan la metrópoli, a escenas en que los peatones en las calles caminan apresurados todo el tiempo. El Perú, en la época de esta película, es un país asfixiado entre los problemas del terrorismo, la crisis económica y la corrupción del primer gobierno de Alan García (1985-1990), considerado uno de los peores de la historia republicana. Nuevamente estamos ante un caso en que el cine, como discurso artístico, manifiesta su preocupación ante una situación puntual --la pobreza y marginalidad estructurales como consecuencia de regímenes corruptos y a veces autoritarios-- y desde un registro de carácter realista no solo se ocupa de esa coyuntura y la cuestiona sino que abre la vía al conocimiento y difusión de aquella. Para ello, como en el caso de Chaski, las estrategias y planteamientos son diversos y obviamente no solo se reducen a técnicas del uso de la cámara. Existe una profunda y muy estudiada ideología en la obra de arte que lleva a elegir el por qué de este cuestionamiento. Si bien la influencia del Neorrealismo es notoria y fundamental, Chaski aporta su propia mirada y su propio discurso.

Los cineastas de Chaski siguen a Juliana y al grupo de chicos mendicantes, a quienes ella se ha unido. Ellos entregan sus "ganancias" del día, producto de sus actividades marginales en la calle, a un hombre maduro, que los instruye en la tarea diaria de la sobrevivencia, inventa leyendas sobre su vida y castiga cruelmente a los chiquillos si incumplen las reglas que ha impuesto. Así, en la Lima de fines del siglo veinte, se reproduce el esquema decimonónico de Oliver Twist, la célebre novela de Charles Dickens, como bien ha apuntado Ricardo Bedoya. (277)

Siendo Lima una ciudad que se identifica como marginal y miserable, el trabajo de Chaski, aparte de las dramatizaciones grupales que exige el guion de René Weber, toma cada cierto momento un carácter de reportaje sobre las carencias en esta urbe de acero y cemento, pero también de cinturones de pobreza, 
capaz de albergar, como en un caos perpetuo, a millones de almas, pero sin garantizarles a ellas absolutamente nada. Juliana se hace pasar por un muchacho, y para ello se corta el pelo. Solo así podrá ingresar en el grupo de chiquillos que ya lleva un largo tiempo cantando en los autobuses o ingeniando maneras de pasar la jornada.

La de Juliana no solo es una frustración, no solo es dejar de ver a su madre por un largo tiempo, no consiste solamente en aceptar, sin reclamos, un modo de vida miserable. En verdad, ella, como cualquier chica de su edad, aspira a una existencia más justa y edificante. Es como si la inequidad sistemática y prolongada constituyera la razón de ser de este enclave convertido en ciudad capital.

El final de la película intenta acercarse a los legítimos sueños de los niños de la calle, pasajeros de un autobús que recorre la ciudad nocturna con sus luces brillantes, y genera una sensación de optimismo, pero al mismo tiempo, sugiere una ensoñación, como para olvidar por un momento los maltratos y las miserias.

El crítico Ricardo Bedoya, autor del único volumen sobre la historia del cine peruano hasta la fecha ${ }^{2}$ ha señalado que el final de Juliana evoca el de Milagro en Milán (1951), una más de las célebres cintas de Vittorio de Sica (278), preclaro representante del Neorrealismo, movimiento surgido en Italia en plena Segunda Guerra Mundial. Roberto Rossellini (Roma, ciudad abierta; Alemania, año cero, Paisá) y Luchino Visconti (Obsesión, La tierra tiembla, Bellísima) fueron asimismo los abanderados de esta escuela, que postulaba el trabajo con gente común en vez de actores profesionales o el rodaje en la calle, en oposición a los clásicos estudios o locaciones. Desde su nacimiento, la corriente neorrealista siempre ha constituido una gran influencia y referente para la gran mayoría de las

${ }^{2}$ Durante el gobierno de transición del Dr. Valentín Paniagua, instalado en el año 2000, después de la fuga y posterior renuncia a la Presidencia del dictador Alberto Fujimori, fue creada la Comisión de la Verdad y la Reconciliación (CVR), presidida por el Dr. Salomón Lerner, entonces rector de la Pontificia Universidad Católica del Perú. El informe final de la CVR estima que 70 mil personas fueron las víctimas de la guerra interna (1980-2000), sobre todo en la zona andina del Perú. 
CATEDRAL TomadA: Revista de crítica literaria latinoamericana / Journal of Latin American Literary Criticism Imágenes de sobrevivencia: del realismo urbano del Grupo Chaski al Perú contemporáneo de Claudia Llosa.

representaciones de la marginalidad y la pobreza que se han realizado en América Latina.

El trabajo del Grupo Chaski puede interpretarse como el de la representación de un patetismo urbano, de profunda crudeza, en medio de un panorama trágico para el Perú y América Latina. Desarrollado en los años 80, este trabajo se inscribe en la llamada "década perdida", considerada como tal no solo en el aspecto económico, sino por la presencia de dictaduras militares en el Cono Sur (Argentina, Brasil, Chile, Uruguay), brutales regímenes de facto guiados por una lucha anticomunista que causó miles de víctimas, una herida aún abierta hoy en el continente.

\section{La fantasía neoliberal en Perú}

En los años 90, a partir del Consenso de Washington, que decidió el destino económico de la década para América Latina, y la adopción de políticas neoliberales en distintos países de la región (Brasil, Argentina, Colombia, Bolivia, México, Perú), se propone una reforma del aparato estatal, se considera la privatización de empresas, una nueva política tributaria, y se impone la idea del libre mercado, el cual se autorregularía, sin la intervención de ningún mediador.

Los años 90 significaron una época de mayor pobreza y marginalidad para los excluidos de las reformas neoliberales. En palabras de David Harvey:

Neoliberalism is in the first instance a theory of political economic that proposes that human well-being can best be advanced by liberating individual entrepreneurial freedoms and skills within an institutional framework characterized by strong private property rights, free markets, and free trade. The role of the state is to create and preserve an institutional framework appropriate to such practices. (2) 
Así definido, el neoliberalismo impulsó la presencia del capital privado y la creciente presencia de compañías multinacionales en América Latina, reestructurando el esquema económico de cada país y generando, como consecuencia inmediata, millonarias ganancias para los inversionistas, quienes de pronto, hallaron un nuevo "paraíso artificial" en nuestros países, tan golpeados como victimizados a lo largo de la historia moderna.

Continuando una tradición continental, los gobiernos de turno evitaron plantear una política de redistribución de ganancias y la gestión de programas sociales. Al contrario, en países como Perú, el gobierno dictatorial de Alberto Fujimori (1990-2000), quien actualmente cumple una pena de cárcel por violación de derechos humanos y corrupción, estimuló permanentemente al capital foráneo, sin restricción alguna.

Por cierto, desde 2009 Fujimori cumplía una condena de veinticinco años por violación de derechos humanos y corrupción, pero recientemente fue indultado por el actual presidente Pedro Pablo Kuczinsky, a su vez, según la prensa peruana, comprometido en turbias negociaciones financieras.

Más adelante, ya en el siglo XXI, el Perú ingresó, como otras economías de América del Sur, a una etapa de relativa prosperidad, gracias al alza del precio de los minerales y materias primas en el mercado mundial. Entonces, surgieron -dogmáticos y triunfalistas-- los discursos de los presidentes Alejandro Toledo (2001-2006), Alan García (2006-2011) y Ollanta Humala (2011-2016), hoy comprometidos en escandalosos casos de corrupción. Humala actualmente está en prisión junto a su esposa Nadine Heredia.

Los gobiernos de turno, con el apoyo de la mayoría de medios de comunicación, crearon una cierta noción positiva del país, basada en la ilusión del crecimiento económico y la fantasía de las bondades del modelo neoliberal. Para fortalecer esta idea, se tomó como un referente el "boom" de la gastronomía nacional, que fue más que todo el invento de cierta elite y de sus pretenciosos intereses. Al mismo tiempo, registrando una cuota desmedida de chovinismo, las instituciones gubernamentales auspiciaron campañas de promoción, como la de 
CATEDRAL TomadA: Revista de crítica literaria latinoamericana / Journal of Latin American Literary Criticism Imágenes de sobrevivencia: del realismo urbano del Grupo Chaski al Perú contemporáneo de Claudia Llosa.

"Marca Perú", o fijaron expresamente determinados días del año para celebrar las cualidades de comidas y bebidas distintivas de la nacionalidad peruana.

A propósito de los discursos enmarcados en celebrar los aciertos del crecimiento económico, consultores como Rolando Arellano se han referido, igualmente, al surgimiento de una "nueva clase media" en el Perú, que tendría sus raíces en los millones de habitantes que migraron desde otras regiones a Lima:

Solo al llegar a las ciudades, cuando las clases altas y medias tradicionales les impidieron el ingreso y los ignoraron comercialmente, se empezaron a dar tres características que ayudarían a convertirlos en clase media (CM). Primera, la propiedad de vivienda, ya que, al tener que asentarse en la periferia de las ciudades, se hicieron dueños de terrenos que nadie reclamó por considerarlos sin valor. Segunda, posibilidad de crecimiento económico, pues al no recibir oferta de las empresas formales debieron generar empresas para producir los bienes y servicios que necesitaban. Tercera, mayor bienestar, porque al estar fuera del círculo económico tradicional afrontaron menores costos de vida. Ello los llevaría luego a tener capacidad de gasto discrecional (más allá de sus necesidades básicas) y a adquirir un sentimiento de autoestima social, que terminan por definirlos como clase media. (Arellano)

Arellano, un estudioso de la migración de provincias a la capital, es también autor, con David Burgos Abugattás, del libro Ciudad de los Reyes, de los Chávez, los Quispe..., cuyo título, no carente de ironía, describe e interpreta la "Nueva Lima" del siglo XXI. 


\section{Claudia Llosa, la mirada femenina en el cine peruano después de la globalización.}

En el año 2006, la cineasta peruana Claudia Llosa estrenó su opera prima, Madeinusa, un acercamiento al mundo andino que bien puede leerse como un testimonio social, antropológico e incluso etnográfico. La cinta es particularmente explícita en la representación de un milenario "tiempo santo": un periodo del calendario católico que nos invita a la reflexión y a la humildad, en el contexto del sacrificio, pasión, muerte y resurrección de Jesucristo.

Sin embargo y al mismo tiempo, durante la Semana Santa, "todo está permitido", entre los pobladores de Manayaycuna, el ficticio pueblo donde ocurre la historia de Madeinusa. En este contexto de liberación colectiva, asistimos al relato que protagoniza Madeinusa, esta vez la protagonista, cuya mayor aspiración es viajar a Lima, la capital del Perú, para reencontrarse con su madre. Tanto Madeinusa como su hermana viven con su padre, en medio de una atmósfera incestuosa, un hecho que llamó la atención al momento del estreno del filme ya que esta "vida en común" podría connotar una mirada negativa del mundo andino. Casi como el hecho de que la población se embriague, baile y celebre desaforadamente, al compás de una música que se torna estridente y va acompañada por incesantes fuegos artificiales.

Además, Madeinusa constituye una mirada inédita a ese lejano universo de los Andes, tradicionalmente un espacio ignorado de la "vida oficial", que, en los años 70 y 80, motivó un cine basado en la representación del maltrato, la violencia o la explotación hacia el poblador de esta región. Ello ocurre, por ejemplo, en El caso Huayanay: testimonio de parte (1981), de Federico García, veterano realizador peruano, quien se inspiró en la historia real del ajusticiamiento de un abigeo a manos de los miembros de una comunidad rural.

Mientras los Andes peruanos son percibidos como ambientes distantes y enrarecidos, lejanos de los centros de poder y decisión ubicados en la Costa, no podemos soslayar el hecho de que fue en esta región, en el departamento de 
CATEDRAL TOMADA: Revista de crítica literaria latinoamericana / Journal of Latin American Literary Criticism Imágenes de sobrevivencia: del realismo urbano del Grupo Chaski al Perú contemporáneo de Claudia Llosa.

Ayacucho, donde se originó la barbarie terrorista de Sendero Luminoso, que inició la guerra interna en Perú en el año $1980^{3}$.

El mundo de Madeinusa tiene incluso elementos idílicos, de cierta magia: la protagonista mantiene sus sueños, aún desde su condición de mujer y de su lugar en la cocina de su casa. Sin embargo, tanto la casa como el pueblo que albergan a Madeinusa muestran el secular abandono y atraso de las comunidades rurales frente a las urbes de la costa peruana, más bien reflejos inciertos y anónimos de una modernidad influenciada y dependiente de los países del Norte industrializado, como ocurre en otras megalópolis latinoamericanas: Buenos Aires, Rio de Janeiro, Santiago de Chile o México D.F.

Así es, no solo por su estratégica ubicación a orillas del Océano Pacífico, sino por su condición de capital de la República, Lima se ha convertido en una ciudad a donde los habitantes de otras zonas del Perú migran por obligación, en busca de mejores condiciones de vida. Ello explica, ciertamente, el deseo explícito de Madeinusa --inconforme con su rutina familiar y frustrada con la vida comunal y rural-- de viajar a Lima y reencontrar a su madre. A ella le han relatado historias casi de ensueño sobre una gran ciudad que no tiene vínculo alguno con los paisajes que recorre a diario, las lagunas, los cielos despejados y azulinos, las casas una al lado de la otra, en Manayaycuna, un poblado detenido en el tiempo.

Contradictoriamente, la cámara fija y registra este panorama, que evidencia pobreza o escasez, con una brillante paleta de colores. Así, las tomas de los días soleados inciden sobre cierto optimismo, sobre un mañana que está en la conciencia de la protagonista. La estética que prima en esta película de Claudia Llosa apuesta por los brillos del sol, por las tomas de una naturaleza sana y fértil. Su relato es, en este sentido, de una naturaleza casi "pastoril", como en las obras de Cervantes u otras de la edad áurea de la literatura española.

${ }^{3}$ En 100 años de cine en el Perú. Una historia crítica, el profesor Ricardo Bedoya culmina su exploración en el año 1995, un siglo después de la invención del cinematógrafo. El autor confirma que, entre enero de 1980 y diciembre de 1990, la cinematografía nacional solo produjo 37 obras. El "autogolpe", en 1992, del entonces gobernante Alberto Fujimori, cercenó, no solo cualquier propuesta cinematográfica sino las diversas expresiones culturales. 
En Madeinusa, la llegada de Salvador, un forastero de raza blanca, representará la oportunidad que esperaba la protagonista para dejar ese mundo en el que ha vivido desde su nacimiento. Mientras su hermana muestra una mayor fidelidad al padre y al pueblo, Madeinusa es una rebelde silenciosa, que alimenta sus propios sueños. En este contexto, que comienza a perturbarse, es simbólica, por ejemplo, la maleta en la que ella guarda, como tesoros privados, lápices de labios, revistas, aretes... elementos propios de la cultura de consumo y la moda occidental.

Mientras el "tiempo santo" se extiende y constituye, a la vez, parte importante de la narración de la película, nada es motivo de escándalo, las danzas así como el excesivo consumo de licor por parte de los pueblerinos nos hablan de una "inversión de valores", de un ritual muy similar al que Mijaíl Bajtín estudia a propósito del carnaval medieval ${ }^{4}$ En estas imágenes, aprendemos más del pueblo, escenario de Madeinusa, de sus costumbres, del modo de ser de sus habitantes. Se trata de un lugar alejado de la civilización, lejos de la costa que es la región más industrializada del Perú.

Claudia Llosa, en una entrevista concedida a la revista Butaca, de la Universidad de San Marcos (Lima), revela aquello que realmente quiso proyectar en su filme inicial:

Cuando empecé a escribir Madeinusa, quería reflexionar acerca de la relación ambivalente que existe entre el deber aprendido y el deseo

${ }^{4}$ En La cultura popular en la Edad Media y en el Renacimiento: El contexto de François Rabelais, Mijaíl Bajtín estudia el carnaval medieval, sus formas y representaciones. Sostiene que las fiestas religiosas poseían un aspecto cómico popular y público. Las celebraciones del "tiempo santo" que se muestran en Madeinusa pueden vincularse a las que narra y examina Bajtín. El autor refiere que, frente a las celebraciones de la Iglesia y el Estado oficial, las fiestas del pueblo constituían un mundo aparte, como un segundo mundo. En más de una escena de la película de Claudia Llosa, durante los festejos del "tiempo santo", se ve, por ejemplo, a hombres con máscaras que tienen, a manera de una nariz, una alusión fálica, un elemento inadmisible en la tan cerrada y prejuiciosa cultura católica. Más aún, Bajtín sitúa el origen de estas celebraciones populares en un mundo primitivo, en el cual ni siquiera existían instituciones. En otro momento, define al carnaval como un periodo de "inversión de valores". En Madeiunsa, ello equivale a la "suspensión" de lo sagrado, hecho que permite todas aquellas celebraciones vinculadas a la peculiar cosmovisión del pueblo. 
CATEDRAL TOMADA: Revista de crítica literaria latinoamericana / Journal of Latin American Literary Criticism Imágenes de sobrevivencia: del realismo urbano del Grupo Chaski al Perú contemporáneo de Claudia Llosa.

oculto, innato. Eso deriva ciertamente al sexo pero también a muchas otras aristas. De allí los otros subtemas relevantes de la película. La sensibilidad inconsciente o consciente está estrechamente ligada al deber de la no indiferencia. Madeinusa habla de una ceguera más que oportuna, que hace ojo nulo a muchas cosas, pero señala otras, que pueden llevarnos a analizar la situación política y social que vivimos en el Perú, a los que muchos hacemos ojo nulo a la vez. (Llosa, "Racismo" 25)

En suma, Madeinusa marca el inicio de una nueva etapa en el cine peruano, de una manera similar a las cintas mexicanas $Y$ tu mamá también y Amores perros, Ciudad de Dios (Brasil), y La ciénaga (Argentina), que en los primeros años del presente siglo representaron un encomiable nuevo giro en el mapa del cine latinoamericano. No solo la internacionalización del cine peruano se ha hecho más visible desde entonces, sino que, progresivamente, han surgido y se han hecho realidad otros valiosos proyectos. Los trabajos de los hermanos Daniel y Diego Vega (Octubre, El mudo), Javier Fuentes-León (Contracorriente, El elefante desaparecido) o Joel Calero (La última tarde) han generado triunfos a nivel global, reconocimientos que ahora resultan más familiares y cercanos.

\section{La teta asustada, un filme peruano en el universo del cine internacional}

La segunda obra de Claudia Llosa, La teta asustada, se estrenó internacionalmente en 2009, después de obtener el Oso de Oro, máximo galardón del Festival de Berlín ese mismo año y fue nominada al Oscar como Mejor Película Extranjera. No solo el hecho de que la actriz Magaly Solier sea también la protagonista de La teta asustada, como lo fue de Madeinusa, marca esa casi necesaria continuidad que simbolizan ambos filmes.

La directora Claudia Llosa deja el ambiente mágico pero a la vez enrarecido de un pueblo andino para trasladarse a las periferias de Lima que los 
habitantes de la urbe solían conocer como el Cono Sur, el Cono Norte o el Cono Este. Rodada en parte en Manchay, un poblado marginal y alejado de la Lima moderna, neoliberal y consumista, esta cinta nos presenta a un grupo de familiares y vecinos que son los migrantes obligados de la guerra interna. Huyendo del conflicto, de las hordas de Sendero Luminoso o de las Fuerzas Armadas, estos habitantes de una Lima tradicional que los rechaza sobre todo por su otredad y extrañeza, tratan de construir su mundo, sus esperanzas, su derecho a pensar en un futuro promisorio. La representación cinematográfica se convierte esta vez no solo en una sucesión de hechos derivados de un trauma que deviene en una liberación sino que, a través de la continuidad de unas imágenes muy elaboradas, transforma esta transición o viaje en una historia colmada de matices intensos, unas veces recurriendo a situaciones muy íntimas y conflictivas y otras a hechos más serenos. De esta manera, el cine como arte no solo se expresa a través de un discurso estético o que se abre a un amplio y deseado imaginario social sino que reside en su más íntima esencia una vocación por acercarse a la historia reciente de un país como el Perú y los hechos que sus habitantes vivieron, soportaron o de los cuales fueron víctimas.

Al comienzo de La teta asustada, la cámara registra a una anciana que yace en una cama y canta en quechua un horrible recuerdo: el haber sido ultrajada sexualmente durante la época más dura de la guerra interna. De pronto, deja de cantar y expira. Es cuando Fausta, precisamente Magaly Solier, se inclina ante el cuerpo sin vida, y a la vez, entona una canción en quechua.

De inmediato, situamos una ventana, a través de ella se observa la ladera de un cerro sobre el cual se levantan viviendas de esteras o de cartones. Esta visión confirma la realidad del ambiente que habita Fausta, quien buscará una primera liberación. Años después de la guerra interna y ahora establecida en Lima, Fausta, en parte por la coyuntura socioeconómica neoliberal, tiene que afrontar otra batalla, quizá más dura, más íntima pero también necesaria para su liberación definitiva como mujer y persona. La teta asustada: 
CATEDRAL TomadA: Revista de crítica literaria latinoamericana / Journal of Latin American Literary Criticism Imágenes de sobrevivencia: del realismo urbano del Grupo Chaski al Perú contemporáneo de Claudia Llosa.

Está basada en el estudio médico-antropológico de Kimberly Theidon intitulado Entre prójimos: el conflicto armado interno y la política de la reconciliación en el Perú (2004). En dicho libro, Theidon indaga el trauma de los indígenas quechua-hablantes de la región de Ayacucho que experimentaron abusos y violaciones reiteradas por parte tanto de los miembros del grupo terrorista Sendero Luminoso como del ejército peruano durante los años de la guerra interna (1980-2000). En algunas de las entrevistas recogidas por Theidon, las mujeres cuentan cómo los llakis (penas o males en quechua) se acumulan en sus cuerpos a causa de la violencia recibida, para luego ser transmitidos a sus hijos en el vientre materno y mediante la lactancia. Este mal es denominado "la teta asustada". (Llosa, "Realidad" 46)

En esta segunda película, Llosa marca la diferencia respecto a la economía y el mundo rural que se mostraba en Madeinusa. Mientras en aquélla las hermanas dependían del padre, en La teta asustada, ante la urgencia de organizar un funeral para su madre y no contar con los medios para ello, Fausta se emplea en la casa de una mujer visiblemente perteneciente a una clase acomodada, quien es pianista, y que ni siquiera conoce el verdadero nombre de su empleada.

Al requerir sus servicios o, de pronto, al escucharla cantar, la propietaria de la residencia demuestra un mayor interés en ella, mas nunca se forja una relación estrecha o afectiva entre ambas. Este hecho connota radicalmente no solo las enormes distancias entre estratos opuestos en una pirámide social tan marcada e injusta como la del Perú, sino la ausencia de manifestaciones como el respeto o la tolerancia, que ni siquiera asoman como el referente de un vínculo entre dos personas que habitan temporalmente el mismo espacio.

Es el jardinero, quien frecuentemente va a trabajar a la casa, el personaje con el que Fausta sí logra establecer comunicación, aunque su timidez y reserva siempre dejan un espacio en el vacío, como un territorio por descubrir. Es, asimismo, un acierto del filme, el haber logrado marcar la frontera entre lo 
público y lo privado a partir de la puerta levadiza del garaje de la casa. Cada vez que alguien llama a la puerta, crece la ansiedad y la desconfianza en Fausta.

Curiosamente, cuando la puerta se eleva, constatamos que a solo unos metros existe un mundo en permanente ebullición: un mercado de abastos donde la gente compra, vende, camina, interactúa, conversa... Es la expresión de la vida diaria, tal cual, sin matices, ni añadidos, una vida de la cual Fausta se ha alejado por voluntad propia.

Haber sido traumatizada por el mal conocido como "la teta asustada", la ha convertido en una joven que rehúye casi todo, que prefiere el silencio, la soledad, que razona al interior de su mente, que prefiere explorar y observar desde la distancia, que ha elegido mantener la pureza de su individualidad a toda costa antes de entregarse --porque bien podría hacerlo--, por ejemplo, al conocimiento y recorrido por la gran ciudad: esa Lima de centros comerciales hipermodernos, luces de neón, cadenas de restaurantes y grandes avenidas, que apenas se deja ver en el filme, pero que constituye el territorio que está "más allá", aparentemente muy lejos de los escenarios donde se desarrolla la cinta.

La férrea voluntad de Fausta se asemeja, en parte, al sueño, al principio bucólico y luego transgresor de Madeinusa. Su rostro se muestra constantemente nervioso, inseguro, como si estuviera esperando un momento que nunca llegará. Los primeros planos del rostro de Fausta nos remiten a la categoría conocida como "imagen-afecto", la cual Gilles Deleuze propuso en relación a la importancia del rostro y de sus facciones, como parte de la representación fílmica: "there is no close-up of the face, the face is in itself close-up, the close-up is by itself face and both are affect, affection- image" (88).

En este caso, la cineasta Claudia Llosa prefiere una estética del silencio y la probable autoculpabilidad o el miedo --un tanto a la manera de Ingmar Bergman, precisamente en El silencio o en El Séptimo Sello--, para representar el recorrido de una migrante, víctima de la violencia. Pero el tránsito de Fausta no es el mismo que el de Gregorio, el niño retratado por el Grupo Chaski. Este menor, 
CATEDRAL TOMADA: Revista de crítica literaria latinoamericana / Journal of Latin American Literary Criticism Imágenes de sobrevivencia: del realismo urbano del Grupo Chaski al Perú contemporáneo de Claudia Llosa.

sorprendido por la urbe inmensa y desordenada, no encontraba más remedio que enfrentarse a ella en una suerte de constante aprendizaje.

La ciudad era --es aún-- ese monstruo al que no se llegaba nunca a vencer pero con el que se convivía, así fuera a contracorriente. En cambio, desde su mutismo, desde su inexpresividad, desde el soportar lo que los otros --familiares o allegados-- le dicen, Fausta no necesariamente prefiere conocer la ciudad o buscar amistades. Como Gregorio, ella no tiene dinero, pero consigue un empleo subalterno en una residencia ubicada en una de las zonas "exclusivas" de Lima, si prestamos los términos de una asfixiante publicidad y las expresiones de los beneficiados del neoliberalismo, a quienes caracteriza una escandalosa huachafería, tema que el Premio Nobel de Literatura, Mario Vargas Llosa, ha diseccionado hasta la burla más cruel y extrema como una de las expresiones esenciales de la vida peruana.

Tampoco Fausta elige el camino de Juliana. Es que las circunstancias de su vida son distintas. Los personajes del Grupo Chaski sufren el trauma de la pobreza, mientras Fausta no puede olvidar la violencia del conflicto armado. Unos y otros son víctimas. El Perú, con sus constantes crisis y carencias, da lugar a estas identidades y conciencias no solo disfuncionales sino huérfanas de cualquier auxilio. Se trata de niños y adolescentes que aprenden muy rápido a vivir, porque la necesidad los obliga a ello.

Es importante señalar que tanto los largometrajes del Grupo Chaski como Madeinusa no aluden directamente a la presencia de Sendero Luminoso y la respuesta del Estado a través de sus Fuerzas Armadas. Gregorio y Juliana, en plenos años 80, cuando la presencia de Sendero Luminoso ya había ganado amplio terreno en Lima, se centran en una problemática socioeconómica que es común a otros países de América Latina. Treinta años después, la mirada mágica de un ambiente extraño, en Madeinusa, no menciona explícitamente la acción ni la presencia de Sendero (como sí lo hace, en un ambiente similar, Paloma de papel, de Fabrizio Aguilar, o más concretamente, un filme altamente ideologizado como La boca del lobo, de Francisco Lombardi). Solo La teta asustada se referirá 
al conflicto armado, a la guerra interna, pero una vez que esta ha terminado. Se refiere a sus causas, a su gravedad, a sus víctimas. Fausta es una de ellas. Su temor, su reserva, son consecuencias del trauma de la guerra.

Las primeras migraciones desde los Andes a Lima se produjeron en los años 50. Durante el gobierno militar de Juan Velasco Alvarado (1968-1975) las zonas marginales de Lima, como las que muestra La teta asustada, eran conocidas como "pueblos jóvenes". En Planet of Slums, un lúcido ensayo sobre aquello que representan las también llamadas "barriadas", Mike Davis sintetiza cómo los habitantes de las zonas periféricas o cinturones de pobreza de las grandes urbes en el aún llamado Tercer Mundo luchan por su sobrevivencia:

Everywhere in the Third World, housing choice is a hard calculus of confusing trade-offs. As the anarchist architect John Turner famously pointed out, "Housing is a verb." The urban poor have to solve a complex equation as they try to optimize housing cost, tenure security, quality of shelter, journey to work, and sometimes, personal safety. For some people, including many pavement-dwellers, a location near a job- say, in a produce market or train station - is even more important than a roof. (27)

En la actualidad, en Lima y otras ciudades del Perú, estos espacios marginales son conocidos como "asentamientos humanos" y durante años han luchado por su legalidad y permanencia. Los elementos de la cultura que representan la vida en estos lugares son graficados en La teta asustada de una manera fiel: los matrimonios en el arenal, las celebraciones que siguen a las bodas, la presencia de una música conocida como "cumbia andina", propia de las poblaciones que migraron a Lima, o el solo hecho de mostrar las escaleras por las cuales los habitantes de estas zonas acceden a sus casas, ubicadas en los cerros o alrededor de ellos. 
CATEDRAL TomadA: Revista de crítica literaria latinoamericana / Journal of Latin American Literary Criticism Imágenes de sobrevivencia: del realismo urbano del Grupo Chaski al Perú contemporáneo de Claudia Llosa.

Presentar de esta manera la realidad palpable y urgente de una Lima transformada, colmada de mezclas y simbolismos, que aparece como una ciudad aparentemente desvinculada de su traumático pasado, ceremonioso y colonial, evidencia una cierta cancelación de seculares prejuicios. Y es que gran parte de estos habitantes marginales, con su propio modo de vida y con todo lo que ha logrado o ha perdido en este viaje sin retorno, representa una época no superada pero que se abre a la esperanza. En aquellos años, los 80, muchos ciudadanos y aun las propias autoridades limeñas pensaban que la violencia armada y suicida del terror no les atañía en lo mínimo, ratificando la importancia de un centralismo asfixiante, que ha significado, a lo largo de la historia republicana, una de las mayores desventajas para integrar a la nación.

Esta violencia y el terror ocurrían, en el imaginario urbano de la capital, solamente en esos pueblos olvidados, lejanos y silenciados de los Andes donde se cometían las atroces violaciones de derechos humanos, invisibles para un Perú oficial, pero finalmente lacerantes y traumáticas para miles de pobladores que no alcanzaron a huir o evitar esas asonadas del horror.

Al final de La teta asustada, cuando Fausta lleva el féretro de su madre al mar, siente que ha llegado el momento de su tan ansiada liberación. Esta escena, colmada de emociones y alegorías --en el contexto de una sociedad que, ahora como antes, prefiere ignorar la tragedia de la guerra interna y aplaudir productos cinematográficos de una escandalosa vulgaridad, planos y frívolos, como Asu Mare (2013) o A los 40 (2014) (los cuales alcanzaron el millón de espectadores, un récord en la historia del cine peruano)-- supone para Fausta iniciar una nueva vida, pero no olvidar. Porque el olvido significaría aceptar la derrota de una valiente generación y la imposición del abuso y la violencia.

Si la película de Claudia Llosa expresa, a partir de la superación del trauma, la posibilidad de forjar un nuevo país o propiciar una reconciliación, no es menos cierto que el Perú aún convive con muchos males, que el terrorismo y las incursiones militares fueron parte de una etapa muy oscura en nuestra historia reciente. Una historia que, con nuevos matices, aún seguimos construyendo, en el 
contexto de una democracia débil, no representativa e incapaz, en los últimos 35 años, de generar consensos y encontrar, más que un acuerdo a largo plazo, una urgente vía de escape y la consolidación de un proyecto orgánico integrador, inclusivo, y que abra espacio a las minorías, sexuales, raciales, regionales, condenadas históricamente al maltrato y al abuso cotidiano.

En 2014, Claudia Llosa retornó al Festival de Berlín, con su tercer filme, Aloft / No llores, vuela (sobre una madre que reencuentra a su hijo veinte años después de haberlo abandonado), rodado en Canadá y presentado, además, en 2015, con una nueva edición, en el Festival de Sundance.

Si bien el estreno de esta cinta en la Berlinale no produjo la apoteosis de La teta asustada en 2009, resulta alentador comprobar que Llosa, una joven realizadora, alcance un prestigio global y es, hoy por hoy, una de las contadas mujeres (al lado de Marianne Eyde, Nora de Izcue, Judith Vélez) en un gremio nacional conducido y dominado por cineastas varones. Con talento y perseverancia, ella ha logrado proyectarse profesional y artísticamente más allá de las fronteras hispanoamericanas y ensaya una propuesta novedosa, distinta y vanguardista, en un medio tan competitivo como el cine en la era de la globalización y caracterizado por el uso de la más avanzada tecnología. Por su parte, en 2016, el Grupo Chaski reapareció con La última noticia, una cinta que retorna a los años de la violencia y retrata la rutina de un periodista radial entre dos fuegos. Más de treinta años han transcurrido desde los trabajos iniciales del Grupo Chaski, que fueron difundidos internacionalmente en festivales como los de Berlín y La Habana.

Tanto los filmes del Grupo Chaski de los años 80 como las dos primeras películas de Claudia Llosa en este siglo se aproximan a situaciones de conflicto, carencia, desprotección, victimización, violencia y son profundos registros de episodios de la historia peruana, siempre marcada por crisis y ambivalencias. No son películas que piden una mirada facilista del espectador, todo lo contrario, cuestionan un orden social injusto, un país entregado a la corrupción y dominado por la violencia, el maltrato, el racismo y otras prejuicios y complejos. La cámara 
CAtedral Tomada: Revista de crítica literaria latinoamericana / Journal of Latin American Literary Criticism Imágenes de sobrevivencia: del realismo urbano del Grupo Chaski al Perú contemporáneo de Claudia Llosa.

se sirve de diversas estrategias y capta instantes, gestos, miradas, paisajes, entornos, calles para construir un discurso que, desde el arte, desmonta y analiza una sociedad enferma. Chaski y Claudia Llosa son cineastas que, en diferentes épocas y con distintos estilos, y a pesar del tiempo transcurrido y de los hechos ocurridos en el periodo que separa sus trabajos, coinciden en un minucioso registro de hechos traumáticos. La conclusión es que la nación sigue un camino trágico y mantiene vigente aquella célebre interrogante formulada en la novela de Vargas Llosa Conversación en La Catedral (1969): ¿En qué momento se había jodido el Perú?

Si el cine configura el rostro de un país, este arte en Perú, huérfano de subvenciones por parte del Estado, aún carente de un marco legal que permita su desarrollo y expansión, tiene la misión de buscar alternativas de expresión y contenido propios, y no convertirse en una simple reiteración de modelos occidentales. En nuestra siempre conflictuada y aún incipiente cinematografía, no es muy ambicioso exigir, a estas alturas, propuestas novedosas y peculiares, que convivan en armonía en la diversidad de géneros, enfoques y estilos, característicos de toda gran industria cinematográfica que ha logrado trascender sus fronteras.

En el Perú de hoy, los gremios de cineastas persisten en la búsqueda de financiamiento local y foráneo, de espacios que permitan mejores condiciones de trabajo y producción, con miras al nacimiento, consolidación y expansión de una industria cuyo objetivo no sea, por cierto, solo producir cintas taquilleras. Ciertas corrientes del cine peruano insisten, con fundamento, en mantener y ampliar la memoria colectiva en una sociedad caracterizada --y es triste comprobarlo a diario-- por el egoísmo y la frivolidad, sentimientos y expresiones que son directa consecuencia de un exacerbado culto a la misma corriente neoliberal. Quienes se adhieren, sin más, a ella, prefieren ignorar la riqueza de las producciones culturales y peor aún, la historia milenaria del país. 


\section{Bibliografía}

Arellano, Rolando. "Cómo nace la nueva clase media". El Comercio, 7 de abril, 2014. http://elcomercio.pe/opinion/rincon-del-autor/como-nace-nuevaclase-media-rolando-arellano-c-noticia-1720904

(Consultado el 30 de mayo, 2016)

Bajtín, Mijaíl. La cultura popular en la Edad Media y el Renacimiento: el contexto de François Rabelais. Barcelona: Barral, 1974.

Bedoya, Ricardo.100 años de cine en el Perú: una historia crítica. Lima:

Universidad de Lima \& Instituto de Cooperación Iberoamericana, 1992.

Davis, Mike. Planet of Slums. London \& New York: Verso, 2006.

Deleuze, Gilles. Cinema 1. Trad. Hugh Tomlinson \& Robert Galeta. Minneapolis: U of Minnesota P, 1986.

Harvey, David. A Brief History of Neoliberalism. New York: Oxford U P, 2005.

Llosa, Claudia. "Quién en el Perú no ha mamado ese racismo". Entrevista de Gustavo Buntinx. Butaca 28 (2006): 23-32.

. "No pretendo retratar la realidad. Pretendo interpretar un tema para sacar discusiones que tenemos reprimidas". Entrevista de Edward Chauca, Rafael Ramírez y Carolina Sitnisky. Mester 39 (1) (2010): 45-55.

McClennen, Sophia. "The Theory and Practice of the Peruvian Grupo Chaski". Jump Cut 50 (2008).

http://www.ejumpcut.org/archive/jc50.2008/Chaski/index.html

(Consultado el 26 de octubre, 2016)

Predrazzini, Yves y Magaly Sánchez. Malandros, bandas y niños de la calle. Cultura de urgencia en la metrópoli latinoamericana. Caracas: Vadell Hermanos Editores, 1992.

Vargas Llosa, Mario. García Márquez: historia de un deicidio. Barcelona: Barral, 1971. 